\title{
(a) OPEN ACCESS \\ Successful management of a pregnant woman with COVID-19 and multiple severe complications
}

\author{
Muhammad Ilham Aldika Akbar, ${ }^{1}$ Khanisyah Erza Gumilar, ${ }^{1}$ \\ Brahmana Askandar Tjokroprawiro (1) , ${ }^{1}$ Renata Alya Ulhaq ${ }^{2}$
}

'Department of Obstetrics and Gynecology, Medical Faculty, Universitas Airlangga, Surabaya, Indonesia

${ }^{2}$ Midwifery Study Program, Medical Faculty, Universitas Airlangga, Surabaya, Indonesia

Correspondence to Dr Brahmana Askandar Tjokroprawiro;

brahmanaaskandar@gmail.com

Accepted 29 August 2021

A) Check for updates

(c) BMJ Publishing Group Limited 2021. Re-use permitted under CC BY-NC. No commercial re-use. See rights and permissions. Published by BMJ.

\section{To cite:}

Aldika Akbar MI, Gumilar KE Tjokroprawiro BA, et al. BMJ Case Rep 2021:14:e243594 doi:10.1136/bcr-2021

243594

\section{SUMMARY}

We report a case of a 36-year-old gravida 2 para 1 woman at 38 weeks of gestation. A caesarean section was performed for severe pre-eclampsia, intrauterine growth restriction and oligohydramnios. The patient suffered postoperative bleeding, and exploratory laparotomy was performed. Uterine atonia, Couvelaire uterus and left adnexal haematoma were found, requiring a supracervical hysterectomy. As COVID-19 pneumonia and superimposed bacterial infection developed, the patient was mechanically ventilated in the intensive care unit. Remdesivir and meropenem were initially administered, but were changed to levofloxacin and ciprofloxacin following antibiotic sensitivity tests. Blood culture grew Enterococcus galinarum. Meanwhile, bleeding of the incisional wound occurred, which was controlled by the cessation of heparin therapy and regular wound care. With intensive monitoring and multidisciplinary management, the patient's condition improved, and she was discharged from the hospital on day 25 from admission.

\section{BACKGROUND}

Since it was first reported in China at the end of 2019, the COVID-19 pandemic has affected massive numbers worldwide. ${ }^{1}$ Up until March 2021, COVID-19 has affected more than 223 countries, with a total of 116521281 confirmed cases and 1589548 deaths. $^{2}$ Indonesia has become the epicentre of COVID-19 in the South Asian region. Until now, there have been 1386556 confirmed cases of COVID-19 in Indonesia and 37547 deaths (a case fatality rate of 2.7\%). ${ }^{3}$ The COVID-19 pandemic can considerably affect vulnerable populations, such as pregnant women, which can lead to increased maternal and neonatal mortality and morbidity. Pregnant women are more susceptible to severe manifestations of respiratory tract infections due to physiological changes in the immune and cardiovascular systems that occur during pregnancy. ${ }^{5}$ Pregnant women infected with SARS-CoV-2 are at an increased risk of maternal death, admission to intensive care unit (ICU), ventilator use, preterm birth and newborn admission to the neonatal ICU. ${ }^{6}$ The presence of comorbidities, such as chronic hypertension, obesity and gestational diabetes, is a risk factor of severe COVID-19 in pregnancy. ${ }^{6}$

We present a complex case of pregnancy further complicated by COVID-19, severe pre-eclampsia (PE) and postpartum haemorrhage (PPH), ultimately resulting in a hysterectomy. In addition to COVID-19, the patient also suffered from bacterial pneumonia, requiring long-term care in the ICU with multiple drug therapy. During treatment, the surgical wound in the abdomen was bleeding due to the adverse effect of heparin administered for anticoagulation. This case is unique because of its complexity, the course of the disease, side effects of therapy and successful multidisciplinary management.

\section{CASE PRESENTATION}

A 36-year-old pregnant woman, gravida 2 para 1 , at 38-39 weeks of gestation was admitted to the hospital with several pregnancy complications, including severe PE, obesity class 3 (body mass index: $41.84 \mathrm{~kg} / \mathrm{m}^{2}$ ), oligohydramnios (amniotic fluid index=3), suspicion of intrauterine growth restriction (IUGR) and COVID-19 with an estimated fetal weight of $2200 \mathrm{~g}$. During the current pregnancy, the patient had attended 10 regular antenatal visits; her blood pressure (BP) was normal (systolic: $90-110 \mathrm{~mm} \mathrm{Hg}$ and diastolic: $60-80 \mathrm{~mm} \mathrm{Hg}$ ). At 38 weeks, however, her BP reached $170 / 110 \mathrm{~mm} \mathrm{Hg}$ with urinary protein of +2 , establishing the diagnosis of severe PE. The patient was initially treated with the anticonvulsant MgSO4 intravenously (4g of intravenous bolus maintained with a dose of $1 \mathrm{~g} /$ hour). At the time of admission, the patient was screened for COVID-19, and the IgG antibody to SARS-CoV-2 was reactive, although her chest radiograph revealed normal findings. A reverse transcription PCR (RT-PCR) test for SARS-CoV-2 was performed to confirm the diagnosis of COVID-19 infection. Fetal wellbeing tests showed an abnormal non-stress test (low variability and late deceleration), oligohydramnios and suspected IUGR. For the severe PE, IUGR and worsening fetal condition, caesarean section was performed, followed by sterilisation. We found meconium-stained amniotic fluid, and the baby was born with a birth weight of $2190 \mathrm{~g}(<5$ th percentile), height of $38 \mathrm{~cm}$, and $1 \mathrm{~min}$ and $5 \mathrm{~min}$ appearance, pulse, grimace, activity and respiration (Apgar) scores of 7 and 8, respectively. After surgery, the maternal COVID-19 molecular test showed a negative result (on admission day 1 (D1)).

On the day after caesarean section, day 2 (D2), the maternal condition deteriorated and the patient's BP and urine output decreased (BP: 100/60 mm Hg, urine output: $160 \mathrm{~mL} / 13$ hours). The patient was given fluid resuscitation, but her condition did not improve. On D3, her BP was still low $(96 / 54 \mathrm{~mm} \mathrm{Hg})$, and laboratory examination revealed severe anaemia (haemoglobin: $3.8 \mathrm{~g}$ / 


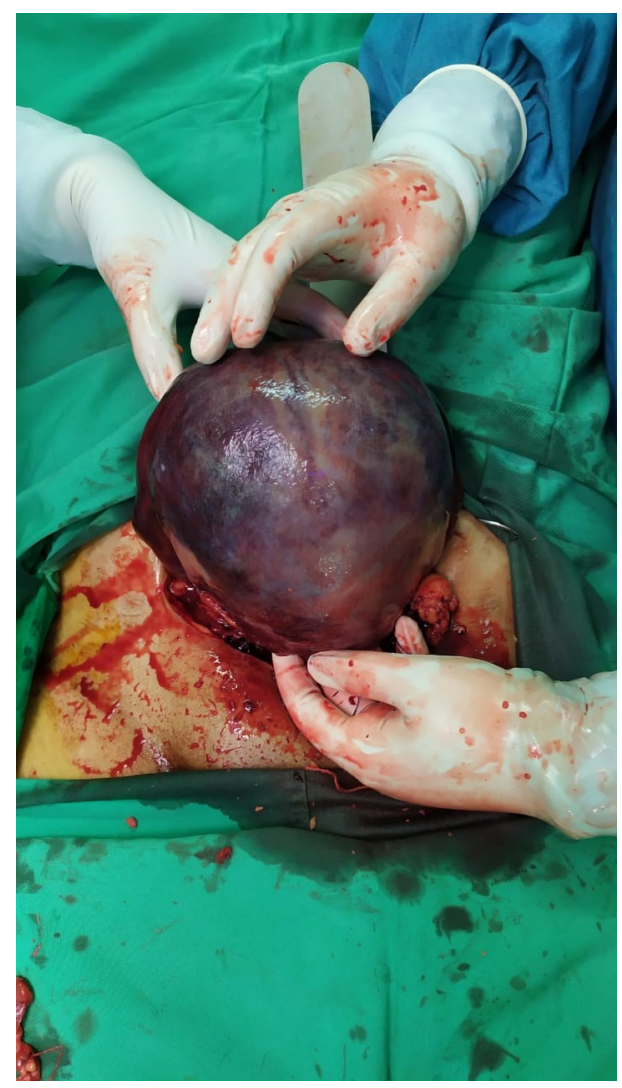

Figure 1 Couvelaire uterus. The purplish-blue discolouration of the uterus is caused by intrauterine bleeding that penetrates into the myometrium.

dL). An ultrasound scan of the abdomen revealed significant free fluid, leading to the diagnosis of internal bleeding. Therefore, an exploratory laparotomy was performed. The uterus was found to be enlarged, atonic and resembled a Couvelaire uterus (figure 1). A Couvelaire uterus is a purplish-blue uterus caused by uterine bleeding that penetrates the myometrium. A haematoma was found in the left adnexa, which was considered the source of intrauterine bleeding. Initially, we tried to perform modified B-lynch procedure, but it was unsuccessful; therefore, we decided to perform a supracervical hysterectomy. We chose not to perform total hysterectomy in this case because the source of bleeding was in the uterine corpus. The cervix was maintained to partially preserve sexual function. The total blood loss during the surgery was $1200 \mathrm{~mL}$ with a fluid input of $2300 \mathrm{~mL}$. The patient received a total of 3 units of whole blood (WB) transfusion before surgery and 2 units of WB during surgery.

The patient was then treated in the ICU using the ventilator mode pressure-synchronised intermittent mandatory ventilation (PSIMV), positive end expiratory pressure of $6 \mathrm{~cm}$ of water, and a fraction of inspired oxygen of $100 \%$, with a global coma scale (GCS) of E4VxM6, and oxygen saturation of 97\%-100\%. The ventilator support was continued after surgery to maintain adequate oxygen delivery, as the patient had severe anaemia which limited oxygen delivery to the tissues. Another consideration was the risk of transfusion-related acute lung injury, which can occur as a result of massive transfusion. On laboratory examination, we found anaemia, hypoalbuminaemia, thrombocytopenia, hyponatraemia and hypokalaemia (table 1). The patient was administered non-steroidal anti-inflammatory drugs, ceftriaxon,e and albumin and underwent packed red cell

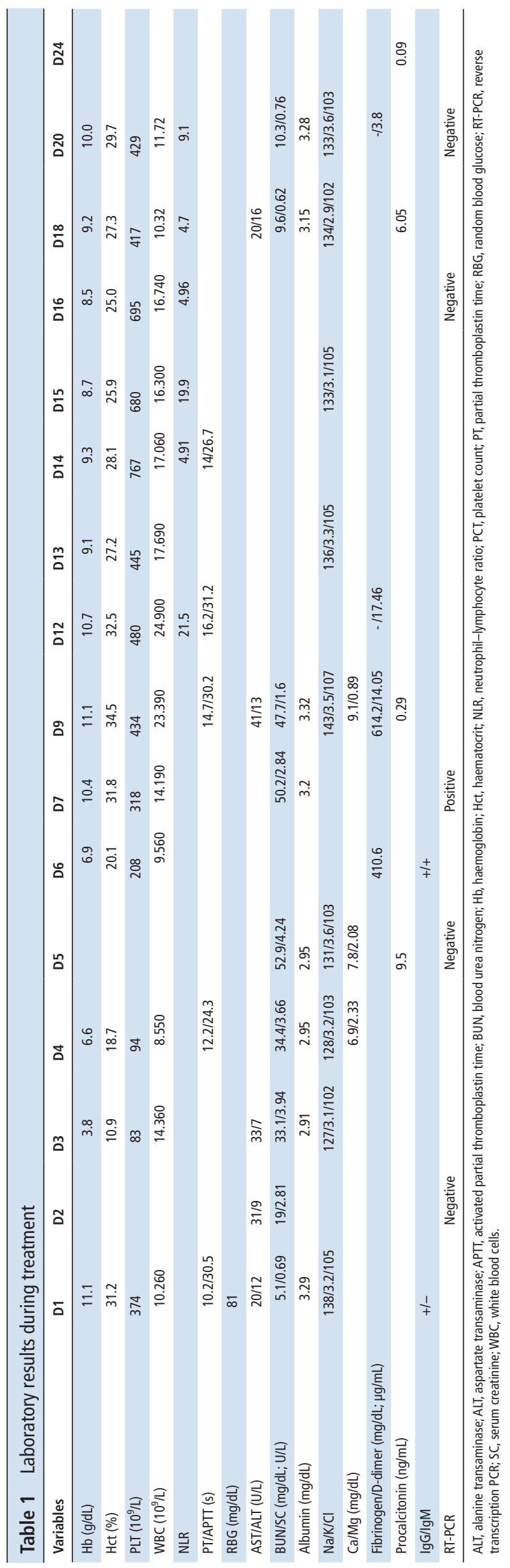




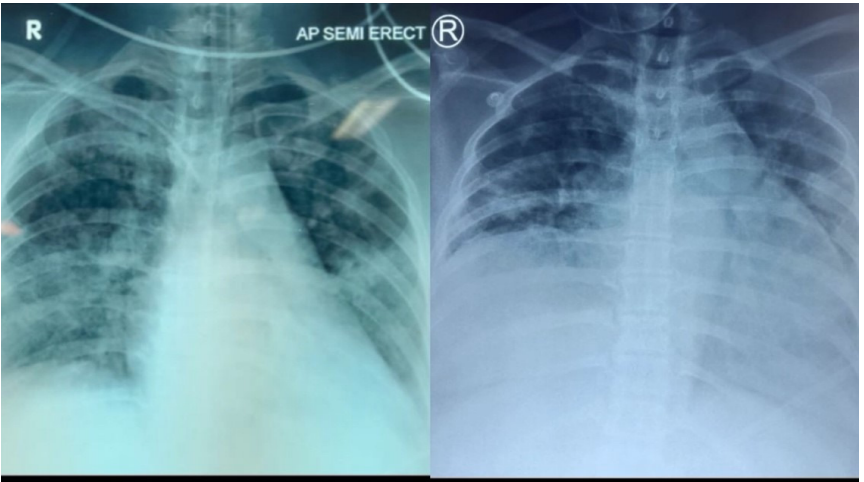

Figure 2 Chest radiograph shows progression of the disease. Bilateral infiltrates were seen in the lung fields on day 5 of admission (left). The worsening of lung imaging is indicated by increased infiltrates on day 11 (right).

transfusion and serum electrolyte correction. After 3 days of treatment in the ICU (D4), rhonchi were detected on auscultation of the lungs, which was suspected to be due to pulmonary oedema with pneumonia as a differential diagnosis based on chest radiographic findings shown in figure 2 . As the first line of management, the patient was administered furosemide $10 \mathrm{mg} /$ hour intravenously (to relieve the suspected lung oedema) and intravenous meropenem, while repeated blood culture and SARS-CoV-2 molecular tests were performed. Again, the SARS-CoV-2 molecular test was negative. However, on D7, the RT-PCR for SARS-CoV-2 was positive, and the patient was diagnosed with COVID-19 with superimposed bacterial pneumonia. The pulmonologists commenced administration of remdesivir $100 \mathrm{mg}$ three times per day for COVID-19 pneumonia. Over the next few days, blood culture showed no growth of microbes. During treatment in the ICU, the patient's BP was consistently elevated $(>150 / 90 \mathrm{~mm} \mathrm{Hg}$ ), which was treated by a cardiologist with isosorbide dinitrate and nicardipine. The ventilator was maintained for a week secondary to unstable respiratory function and oxygenation parameter during this period.

On D8, the patient's condition improved, with a GCS of E4V5M6 (completely conscious). Therefore, the patient was removed from ventilator and maintained on a non-rebreathing mask (NRBM) with adequate oxygen saturation (97\%-98\%). On D9, because of increased D-dimer levels, the patient was administered heparin at 400 units/hour intravenously as a prophylactic anticoagulant. Over the next 2 days (D9 and D10), the patient had fever (temperature of $37.8^{\circ} \mathrm{C}$ ) and was administered antipyretics. On D11, the incisional wound in the abdomen was bleeding (figure 3), although the vital signs were normal and the fever had started to resolve. Wound care was performed two times per day using sterile water. Moreover, on D11, the patient was started on convalescent plasma transfusion $200 \mathrm{mg}$ two times per day for 2 days. We performed an ultrasound to evaluate the source of bleeding in the incisional wound and found a haematoma superficial to fascia in the surgical site. The bleeding was suspected to be caused by heparin therapy, and the administration of heparin was stopped on D13. Following cessation of heparin, no incisional site bleeding was observed. We continued to monitor the progression of COVID19, and the fourth (D15) and fifth (D19) RT-PCR results from the nasopharyngeal-oropharyngeal swab samples were negative for SARS-CoV-2. On D18, blood culture showed the presence of Enterococcus gallinarum, which was sensitive to ampicillin, ciprofloxacin and levofloxacin. Therefore, the antibiotics were

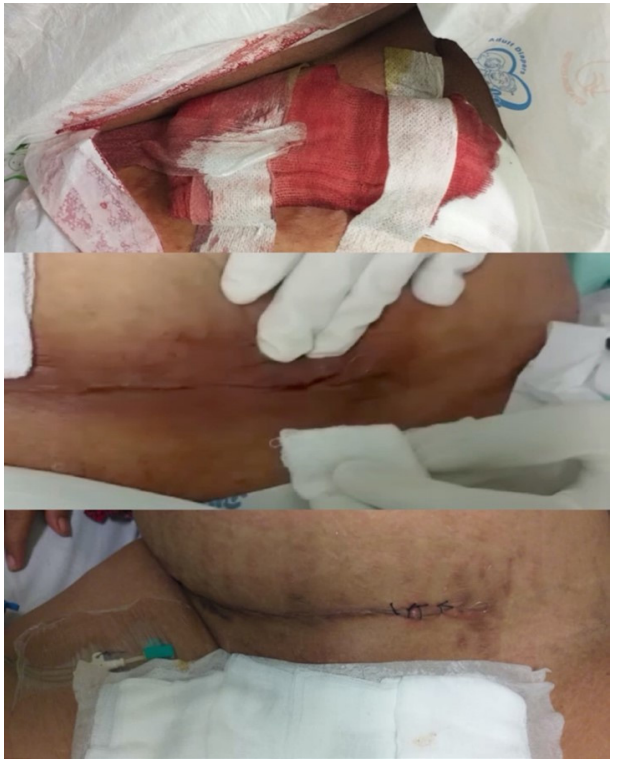

Figure 3 Surgical wound bleeding was caused as an adverse effect of heparin therapy. The gauze was soaked in blood on day 11 of admission (D11) (top). The source of bleeding from the wound incision detected on D11 is seen here (middle). The incision was resutured, and the bleeding stopped after cessation of heparin therapy on day 15 (bottom).

changed to levofloxacin $750 \mathrm{mg}$ once a day and ciprofloxacin $200 \mathrm{mg}$ once a day. The patient's condition improved during the next several days. On D24, the patient had stable vital signs: normal BP (126/73 mm Hg) and good saturation with $\mathrm{O}_{2}$ from nasal prongs (95\%-96\%), and the incisional wound had healed. The patient was discharged on the next day (D25). The timeline of this case is shown in figure 4.

Written informed consent was obtained from the patient for the publication of this case report and its accompanying images.

\section{DISCUSSION}

Although RT-PCR is the gold standard to diagnose COVID-19, in this case, we found that on initial examination the molecular test showed negative results twice. On admission, the patient was suspected of COVID-19 based on clinical signs and results of the rapid antibody test, although the chest radiographic findings were normal. Although this screening method is not ideal, this had to be performed due to limited RT-PCR test in the hospital. On the third swab (D7), the RT-PCR test showed a positive result, and the patient was diagnosed with COVID-19 pneumonia. This case suggests that RT-PCR in SARS-COV-2 is not $100 \%$ sensitive, and there is a possibility of it being false negative. In a meta-analysis involving 12057 patients, the initial false-negative rate of RT-PCR in SARS-COV-2 was from $2 \%$ up to $54 \% .^{7}$ In this case, the possibility of an initial falsenegative result may be related to the disease being in the incubation period, and the number of viral copies being low is to be detected in the molecular test. Therefore, in the management of pregnant patients with suspected COVID-19 based on clinical and laboratory signs, the RT-PCR test should be repeated periodically to minimise the risk of false-negative results. ${ }^{78}$

Severe PE was also found in this case, which may be explained by either the coexistence of true PE with COVID-19 or a severe PE-like syndrome induced by COVID-19. COVID-19 can induce clinical manifestations that resemble severe PE, including hypertension, renal and hepatic involvement, and proteinuria. The differentiation between these two conditions 


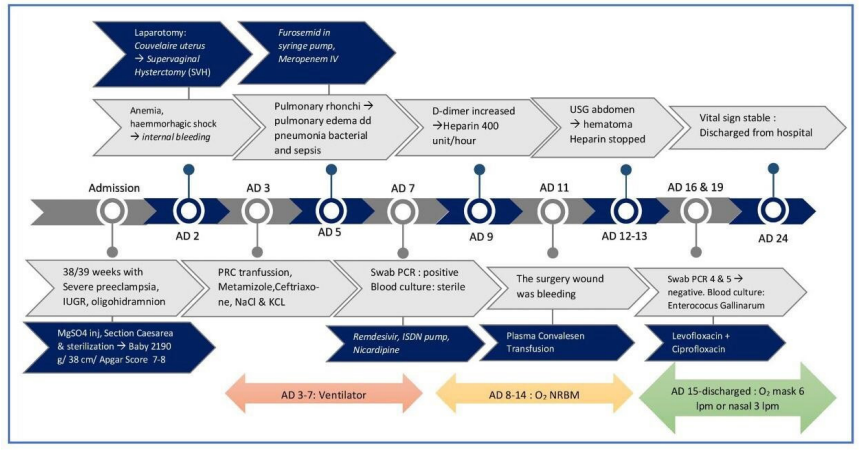

Figure 4 The timeline of treatment and progression of the disease. IUGR, intrauterine growth restriction; NRBM, non-rebreathing mask; USG, ultrasonography.

is difficult. The soluble fms-like tyrosine kinase 1, placental growth factor level and uterine artery Doppler index may differentiate between these conditions. ${ }^{9}$ In this case, we treated the condition as severe PE with COVID-19, and MgSO4 treatment was undertaken to prevent seizures. The diagnosis of PE instead of PE-like syndrome of COVID-19 was established based on the presence of hypertension, proteinuria, hypoalbuminaemia and IUGR in accordance with the International Society for the Study of Hypertension in Pregnancy classification. ${ }^{10}$ The presence of severe PE increases the risk of $\mathrm{PPH}$, which in this case necessitated hysterectomy because of failed conservative treatment during surgery. ${ }^{11}$ However, COVID-19 itself has not been proven to increase the risk of $\mathrm{PPH}$ as per a retrospective study in the USA. ${ }^{12}$

In this case, COVID-19 pneumonia also coexisted with a bacterial infection. The diagnosis of bacterial pneumonia rather than pulmonary oedema was established based on the clinical signs of fever and tachypnoea, pulmonary radiography, a high serum procalcitonin level and a positive blood culture. Cardiac causes were excluded based on the normal echocardiographic findings. Management was aimed at maintaining adequate oxygenation with mechanical ventilation (ventilator mode PSIMV) during treatment in the ICU with a target oxygen saturation of $>95 \%$. After the respiratory function was stable, the ventilator was removed and replaced with an NRBM, and eventually a simple mask or nasal $\mathrm{O}_{2}$. The blood culture later grew E. gallinarum, VanC-harbouring enterococci which have low-level resistance to vancomycin. These enterococci have less impact on nosocomial infection control and only occasionally cause clinical disease. ${ }^{13}$ Sixty percent of infection by E. gallinarum manifest as sepsis within 24 hours. ${ }^{13}$ The main port of entry of this microorganism is from biliary tract $(76.8 \%)$ and abdomen $(7.1 \%) .{ }^{13}$ The source of E. gallinarum bacteraemia in this case is unknown, but the two major surgeries may have played a role. The recommended antibiotics for E. gallinarum infection are either monotherapy with ampicillin or vancomycin, or combination therapy with ampicillin plus gentamicin. ${ }^{13}$ However, in this case, the antibiotic sensitivity test suggested the use of levofloxacin or ciprofloxacin. Remdesivir is used in the treatment of COVID-19 pneumonia and has been shown by the Adaptive COVID-19 Treatment Trial-1 study to reduce the time of recovery in adults with severe COVID-19 infection. ${ }^{14} \mathrm{~A}$ study by Burwick et al, which included 86 pregnant and postpartum women with remdesivir administration, showed a high recovery rate with low incidence of serious adverse events with the drug. ${ }^{15}$ In a group of mechanically ventilated female patients on remdesivir, the survival rate until discharge was $82 \%$, and the overall rate of clinical improvement was $93 \% .^{15}$ In this case, the addition of remdesivir for 10 days improved the clinical and laboratory parameters significantly. Dexamethasone was administered in this case for fetal lung maturity and not for COVID-19 pneumonia. There is no evidence that steroid use may cause harm in COVID-19 infection. ${ }^{16}$ There is insufficient evidence to recommend convalescent plasma in pregnant patients. ${ }^{17} 18$ The rationale of convalescent plasma therapy is to provide specific antibodies against the virus to help the immune system eradicate the pathogen. ${ }^{19}$

The management of COVID-19 in pregnancy with respiratory compromise is to provide adequate respiratory support. In this case, the patient required mechanical ventilation due to respiratory distress and unstable oxygenation. The goal of respiratory support is to maintain an oxygen saturation of $>95 \%$ and reduce tachypnoea and dyspnoea. Oxygen therapy should be administered if the $\mathrm{SpO}_{2}$ values fall below 95\% in pregnant women and below $90 \%$ in non-pregnant women. ${ }^{20}$ The threshold of oxygen therapy in pregnant women is higher due to increased oxygen demand and placental transfer of oxygen to the fetus. ${ }^{20}$

In our case, the incisional site bleeding was attributed to heparin therapy commenced for venous thromboembolism prophylaxis. Our patient had increased D-dimer levels, which is considered prognostic for thrombosis in COVID-19. Coagulopathy has been reported in $>50 \%$ of patients with severe manifestations of COVID-19. ${ }^{21}$ The International Society on Thrombosis and Haemostasis has recommended the prophylactic administration of anticoagulants in patients with COVID-19 to prevent thrombosis and organ damage. ${ }^{22}$ Pregnancy has been considered as a prothrombotic state due to the physiological changes. The presence of COVID-19 increases vascular inflammation, which places pregnant women at risk of thrombosis. ${ }^{23}$ Therefore, anticoagulants should be administered in the management of pregnant women with COVID-19, especially in patients with elevated D-dimer $(>1 \mathrm{~g} / \mathrm{mL}){ }^{23}$ The Society for Maternal-Fetal Medicine supports prophylactic heparin use in critically ill or mechanically ventilated pregnant women with COVID-19. ${ }^{24}$ Clinical studies have shown that the risk of a major haemorrhagic event during heparin therapy for deep venous thrombosis or pulmonary embolism is approximately $4 \% .{ }^{25}$ Heparin therapy in COVID-19 requires intensive monitoring to balance the need for anticoagulation with the risk of bleeding. The decision to use anticoagulants should be based on an analysis of the potential risks and benefits. Risks include postoperative bleeding, as seen in our case, while the benefit of anticoagulation in patients with COVID-19 is the decreased risk of thromboembolic events. In our case, the patient also had thrombocytopenia, which could have contributed to the PPH and the Couvelaire uterus.

This complex case showed a limitation on the diagnosis and management of COVID-19 in pregnancy with multiple complications. COVID-19 can cause multiple direct or indirect complications in pregnancy. The diagnosis of COVID-19 should not be based solely on a molecular test, especially in the very early stage of the disease. ${ }^{7826}$ The complete assessment of clinical findings, laboratory results, chest imaging and other parameters may establish the diagnosis of COVID-19 infection, despite a negative molecular test result. COVID-19 can be complicated by PE which significantly increases the risk of adverse pregnancy outcomes such as PPH. In COVID-19, the presence of complications such as $\mathrm{PE}$ leading to $\mathrm{PPH}$ requires intensive postsurgery observation to minimise the risk of PPH. A postmortem study of 621 patients found that bacterial superinfection was present in $32 \%$ of cases, mainly (95\%) in the form of pneumonia. ${ }^{27}$ If bacterial infection is suspected, blood and sputum cultures 
should be performed, with antibiotic sensitivity testing, to establish the diagnosis. Finally, anticoagulation should be used with caution in pregnant patients with COVID-19 as patients who undergo surgery may be at increased risk of bleeding.

\section{Patient's perspective}

Pregnancy with multiple complications should be treated in a tertiary hospital with adequate facilities and an experienced multidisciplinary team, which is why I could be saved.

\section{Learning points}

- The RT-PCR test for the detection of SARS-CoV-2 should be repeated if the initial test is negative and clinical suspicion remains high. Sequential tests can enhance the diagnostic yield.

- COVID-19 may induce clinical manifestations that resemble severe pre-eclampsia (PE), including hypertension, renal and liver involvement, and proteinuria.

- COVID-19 complicated with PE can increase the risk of postpartum haemorrhage and may require close observation after surgery.

- The possibility of superimposed bacterial infection in COVID-19 pneumonia should always be considered in prolonged hospitalised patients.

- Prophylactic heparin in pregnant woman with COVID-19 needs intensive monitoring of clinical signs of the side effects of heparin to balance the need for anticoagulants with the risk of bleeding, especially in patients who need surgical intervention.

Contributors MIAA was involved in conceptualisation and drafting. BAT was involved in drafting, editing and formatting. KEG was involved in data collection. RAU was involved in data collection and editing

Funding The authors have not declared a specific grant for this research from any funding agency in the public, commercial or not-for-profit sectors.

\section{Competing interests None declared.}

Patient consent for publication Obtained.

Provenance and peer review Not commissioned; externally peer reviewed.

Open access This is an open access article distributed in accordance with the Creative Commons Attribution Non Commercial (CC BY-NC 4.0) license, which permits others to distribute, remix, adapt, build upon this work non-commercially, and license their derivative works on different terms, provided the original work is properly cited and the use is non-commercial. See: http://creativecommons.org/ licenses/by-nc/4.01.

ORCID iD

Brahmana Askandar Tjokroprawiro http://orcid.org/0000-0003-1658-3477

\section{REFERENCES}

1 Zhou P, Yang X-L, Wang X-G, et al. A pneumonia outbreak associated with a new coronavirus of probable bat origin. Nature 2020;579:270-3.

2 World Health Organization. WHO Official Update - Coronavirus Disease 20192021.

3 World Health Organization. WHO Official Update - Coronavirus Disease 2019, 2021. Available: https://www.who.int/emergencies/diseases/novel-coronavirus-2019?gclid=
CjwKCAiAsaOBBhA4EiwAo0_Ano-Xgx7YfYaysoByoFFONwSnCnRTTPzu09Tuk8Id20_ ciaQSs7KydhoCculQAvD_BwE

4 Satgas Covid-19. Data Sebaran Covid-19. 2021.Covid19.go.id.

5 Yang H, Wang C, Poon LC. Novel coronavirus infection and pregnancy. Ultrasound Obstet Gynecol 2020;55:435-7.

6 Allotey J, Stallings E, Bonet M, et al. Clinical manifestations, risk factors, and maternal and perinatal outcomes of coronavirus disease 2019 in pregnancy: living systematic review and meta-analysis. BMJ 2020;370:m3320.

7 Arevalo-Rodriguez I, Buitrago-Garcia D, Simancas-Racines D, et al. False-negative results of initial RT-PCR assays for COVID-19: a systematic review. PLoS One 2020;15:e0242958

8 Böger B, Fachi MM, Vilhena RO, et al. Systematic review with meta-analysis of the accuracy of diagnostic tests for COVID-19. Am J Infect Control 2021;49:21-9.

9 Mendoza M, Garcia-Ruiz I, Maiz N, et al. Pre-eclampsia-like syndrome induced by severe COVID-19: a prospective observational study. BJOG: Int. J. Obstet. Gy. 2020;127:1374-80.

10 Brown MA, Magee LA, Kenny LC, et al. Hypertensive disorders of pregnancy: ISSHP classification, diagnosis, and management recommendations for international practice. Hypertension 2018:72:24-43.

11 von Schmidt auf Altenstadt JF, Hukkelhoven CWPM, van Roosmalen J, et al. PreEclampsia increases the risk of postpartum haemorrhage: a nationwide cohort study in the Netherlands. PLoS One 2013:8:e81959.

12 Wang MJ, Schapero M, Iverson R, et al. Obstetric hemorrhage risk associated with novel COVID-19 diagnosis from a single-institution cohort in the United States. Am J Perinatol 2020;37:1411-6.

13 et alChoi S-H, Lee S-O, Kim TH. Clinical features and outcomes of bacteremia caused by Enterococcus casseliflavus and Enterococcus gallinarum: analysis of 56 cases. Available: https://academic.oup.com/cid/article/38/1/53/356238 [Accessed 2 Jun 2021].

14 Beigel JH, Tomashek KM, Dodd LE, et al. Remdesivir for the Treatment of Covid-19 Final Report. N Eng/ J Med 2020;383:1813-26.

15 Burwick RM, Yawetz S, Stephenson KE, et al. Compassionate use of Remdesivir in pregnant women with severe coronavirus disease 2019. Clin Infect Dis 2020;30:1-14

16 Ryan GA, Purandare NC, MCAuliffe FM, et al. Clinical update on COVID-19 in pregnancy: a review article. J Obstet Gynaecol Res 2020;46:1235-45.

17 Jafari R, Jonaidi-Jafari N, Dehghanpoor F, et al. Convalescent plasma therapy in a pregnant COVID-19 patient with a dramatic clinical and imaging response: a case report. World J Radiol 2020:12:137-41.

18 Grisolia G, Franchini M, Glingani C, et al. Convalescent plasma for coronavirus disease 2019 in pregnancy: a case report and review. Am J Obstet Gynecol MFM 2020;2:100174.

19 Abbas AMet al. Use of convalescent plasma for COVID-19 in pregnancy lessons from other viruses. Am J Biomed Sci Res 2020;9:427-33.

20 Pacheco LD, Saad AF, Saade G. Early acute respiratory support for pregnant patients with coronavirus disease 2019 (COVID-19) infection. Obstet Gynecol 2020;136:42-5.

21 Miesbach W, Makris M. COVID-19: coagulopathy, risk of thrombosis, and the rationale for anticoagulation. Clin Appl Thromb Hemost 2020;26:107602962093814.

22 Thachil J, Tang N, Gando S, et al. ISTH interim guidance on recognition and management of coagulopathy in COVID-19. J Thromb Haemost 2020;18:1023-6.

23 Di Renzo GC, Giardina I, Carlo Di Renzo G. Coronavirus disease 2019 in pregnancy: consider thromboembolic disorders and thromboprophylaxis. Am J Obstet Gynecol 2020:223:135

24 SMFM. Society for Maternal-Fetal medicine management considerations for pregnant patients with COVID-19, 2020. Available: https://s3.amazonaws.com/cdn.smfm.org/ media/2336/SMFM_COVID_Management_of_COVID_pos_preg_patients_4-30-20_ final.pdf [Accessed 5 May 2021].

25 Zidane M, Schram MT, Planken EW, et al. Frequency of major hemorrhage in patients treated with unfractionated intravenous heparin for deep venous thrombosis or pulmonary embolism. Arch Intern Med 2000;160:2369-73.

26 Mair MD, Hussain M, Siddiqui S, et al. A systematic review and meta-analysis comparing the diagnostic accuracy of initial RT-PCR and CT scan in suspected COVID-19 patients. Br J Radiol 2021;94:20201039

27 Clancy CJ, Schwartz IS, Kula B. Open forum infectious diseases bacterial superinfections among persons with coronavirus disease 2019: a comprehensive review of data from postmortem studies. 
Copyright 2021 BMJ Publishing Group. All rights reserved. For permission to reuse any of this content visit https://www.bmj.com/company/products-services/rights-and-licensing/permissions/

BMJ Case Report Fellows may re-use this article for personal use and teaching without any further permission.

Become a Fellow of BMJ Case Reports today and you can:

- Submit as many cases as you like

- Enjoy fast sympathetic peer review and rapid publication of accepted articles

Access all the published articles

Re-use any of the published material for personal use and teaching without further permission

Customer Service

If you have any further queries about your subscription, please contact our customer services team on +44 (0) 2071111105 or via email at support@bmj.com.

Visit casereports.bmj.com for more articles like this and to become a Fellow 